\title{
Relações bilaterais Brasil-Argentina: implicações para a integração regional
}

\author{
Amanda Ferreira ${ }^{I}$ \\ Jonathan de Araújo de Assis ${ }^{I I}$ \\ Julia de Souza Borba Gonçalves III \\ Rúbia Áisa Marcondes da Fonseca ${ }^{I V}$ \\ Vitor Garcia de Oliveira Raymundo ${ }^{V}$
}

\begin{abstract}
Resumo: O objetivo do presente artigo é observar, mediante uma visão construtivista, como se deram as relações bilaterais entre Brasil e Argentina durante o segundo governo de Luiz Inácio Lula da Silva (2007-2010), buscando compreender em que medida tais relações tiveram influência no processo de integração do Mercosul. O governo Lula caracterizou-se pela diplomacia presidencial, na qual a figura do presidente foi decisiva na formulação da política externa. Lula foi um dos presidentes brasileiros que mais realizou viagens oficiais, o que fez com que o relacionamento do Brasil, principalmente com países da América do Sul, fosse cada vez mais próximo. Iniciativas desta natureza permitiram um substancial incremento nas medidas cooperativas, expressas sobretudo na ampliação do comércio dentro da região e consonância nas posições em fóruns multilaterais. Ademais, o período analisado compreende o final do governo de Néstor Kirchner e o primeiro mandato de Cristina Kirchner, na Argentina.
\end{abstract}

Palavras-chave: Brasil; Argentina; Mercosul; integração regional.

\section{Bilateral relations Brazil-Argentina: implications for regional integration.}

\begin{abstract}
The purpose of this article is to demonstrate, through a constructivist view, how were the bilateral relations between Brazil and Argentina during Luiz Inácio Lula da Silva's second government (2007-2010), in an effort to understand if those relations had any influence during the integration process of Mercosul. Lula's government was characterized by presidential diplomacy, in which the president's figure was decisive in the foreign policies formulation. Lula was one of the Brazilian presidents who made more official trips, which made Brazilian relationships, especially with South American countries, were even closer. Such initiatives made possible a substantial increase in cooperative actions, expressed above all on the expansion of trade within the region and consonance in positions in multilateral forums. Furthermore, the reporting period comprises the end of Néstor Kirchner government and Cristina Kirchner first mandate, in Argentina.
\end{abstract}

Keywords: Brasil; Argentina; Mercosul; integração regional.

Artigo recebido em 01/04/2016 e aprovado em 07/04/16. 


Relações bilaterais Brasil-Argentina: implicações para a integração regional
Amanda Ferreira
Jonathan de Araújo de Assis
Julia de Souza Borba Gonçalve
Rúbia Áisa Marcondes da Fonseca
Vitor Garcia de Oliveira Raymundo

\section{Introdução}

Historicamente Brasil e Argentina possuem relações que oscilam entre períodos de rivalidade, competição, tentativas de aproximação e de cooperação. Desde suas formações, a posição que um ocupa na política externa do outro é notável, principalmente ao analisarmos o período como um todo em que as visões mútuas foram aos poucos sendo estabelecidas ${ }^{\mathrm{VI}}$. Os diferentes contextos em que tais países estavam inseridos, o cenário internacional de cada época, as questões internas, os formuladores da política externa, são todos fatores a serem considerados em uma análise das relações bilaterais entre os dois países.

O objetivo do presente artigo é observar, mediante uma visão construtivista, como se deram as relações bilaterais entre Brasil e Argentina no intervalo durante o segundo governo de Luiz Inácio Lula da Silva (2007-2010), buscando compreender em que medida tais relações tiveram influência no processo de integração do Mercosul .Ademais, o período analisado compreende o final do governo de Néstor Kirchner e o primeiro mandato de Cristina Kirchner, na Argentina.

A perspectiva teórica construtivista é aqui adotada porque analisa a realidade como uma construção social na qual as ideias, percepções e ações das partes envolvidas são intersubjetivas, de forma que as relações entre os países, como no caso de Brasil e Argentina, são pautadas pelas concepções e visões mútuas sobre os fatos, sobre o Outro e sobre si perante este Outro. Deste modo, temos que as ideias compartilhadas, co-constitutivas da realidade, são responsáveis por construir a identidade que cerceia as relações entre os Estados, podendo esta encaminhar-se à cooperação/integração ou rumar à discórdia/inimizade.

O construtivismo - aqui considerado em maior parte a partir das ideias de Alexander Wendt - afirma que os agentes são capazes de promover mudanças. No caso, Brasil e Argentina, são artífices das relações entre si, possuem suas próprios interesses e políticas, sendo capazes a partir disso de produzir transformações no cenário em que atuam. Assim, a natureza das interações sociais ocorridas no mundo não é irreversível, podendo haver mudanças no decorrer do tempo e das conjunturas. Dessa forma, a convergência nas tomadas de decisão pode colaborar na superação das desconfianças e transformar, por exemplo, uma relação de rivalidade em uma interação pautada por uma cultura de cooperação. Nesse contexto, segundo Wendt, a criação de instituições e/ou de órgãos multilaterais é uma forma de influenciar e modificar os interesses dos próprios agentes que as criam, o que pode influir também na internalização e institucionalização da identidade construída ${ }^{\mathrm{VII}}$.

O governo Lula foi bastante caracterizado pela diplomacia presidencial, na qual a figura do presidente foi decisiva na formulação da política externa. Lula foi um dos presidentes brasileiros que mais realizou viagens oficiais, o que fez com que o relacionamento do Brasil principalmente com países da América do Sul fosse cada vez mais próximo, fato que permitiu também uma maior criação de políticas cooperativas, ampliação do comércio dentro da região e consonância nas posições em fóruns multilaterais. No caso da relação com a Argentina, isso ficou bastante claro frente às várias visitas de Lula à Argentina e dos Kirchner ao Brasil (apenas no ano de 2007 foram cerca de cinco encontros, levando-se em 
Relações bilaterais Brasil-Argentina: implicações para a integração regional

Amanda Ferreira

Jonathan de Araújo de Assis

Julia de Souza Borba Gonçalve

Rúbia Áisa Marcondes da Fonseca

Vitor Garcia de Oliveira Raymundo

consideração não só os presidenciais, mas também de representantes dos dois países), sendo o clima entre os dois países primordialmente de amizade e busca por ampliação da cooperação.

\section{RELAÇÕES COMERCIAIS ENTRE BRASIL E ARGENTINA}

$\mathrm{Na}$ visão do Ministério das Relações Exteriores brasileiro, os laços do país com a Argentina, seu vizinho e também Estado-membro do Mercosul, são fundamentais para a inserção do Brasil na região e no mundo, além de ser um elemento essencial para a constituição de um espaço regional de paz e de cooperação. O Itamaraty aponta ainda que, em âmbito regional, "as capacidades de Brasil e Argentina representam cerca de dois terços do território, da população e do PIB da América do Sul" VIII. .

Nesse contexto, embora o fluxo das relações comerciais entre Brasil e Argentina tenha sofrido uma significativa redução em 2014, devido, principalmente, à delicada situação econômica de ambos os países ${ }^{\mathrm{IX}}$, o comércio bilateral ainda é de significativa importância para o país brasileiro ${ }^{\mathrm{X}}$. No ano apontado, por exemplo, a Argentina ocupou o terceiro lugar no destino das exportações brasileiras. Além disso, em 2014, o país argentino ocupou o quarto lugar entre os países que o Brasil mais importa, atrás apenas de China, Estados Unidos e Alemanha.

Nesse ano, ainda de que tenha havido uma diminuição de $27,19 \%$ das exportações brasileiras para a Argentina e 14,09\% das importações provenientes desse país, a porcentagem em relação ao total das transações brasileiras foi de 6,34\% das exportações e $6,17 \%$ das importações. ${ }^{\mathrm{XI}}$ Vale ressaltar ainda que no período entre 2003 e 2014 - governo do Partido dos Trabalhadores (PT) -, o Brasil apresentou superávit no comércio bilateral em todos os anos, em oposição ao período 2000-2002, no qual a economia brasileira contabilizou consecutivos déficits. $\mathrm{O}$ auge superavitário brasileiro, no primeiro período citado, se deu em 2011 - com um saldo de cerca de US $\$ 5,8$ bilhões -, dado que contrasta fortemente com o do ano de 2014, que foi de apenas US\$138,8 milhões. Pode-se constatar, portanto, uma redução de aproximadamente $97,6 \%$ do superávit brasileiro nas relações comerciais entre os dois países sul-americanos ${ }^{\mathrm{XII}}$.

Vale ressaltar ainda que tanto as exportações brasileiras quanto as argentinas são compostas majoritariamente por produtos manufaturados. Em 2013, por exemplo, tais produtos corresponderiam a $92 \%$ do total exportado pelo Brasil para a Argentina, dentro os quais se destacam automóveis e máquinas. Além disso, um ponto que chama a atenção nos dois primeiros meses de 2015 é o fato de que embora a quase totalidade de produtos vendidos à Argentina tenha sofrido redução, a exportação de produtos armamentícios sofreu um aumento de $132 \%$ com relação ao mesmo período de $2013^{\text {XIII }}$.

Por fim, segundo o Itamaraty, “o capital brasileiro está presente em diversos setores da economia argentina, como o minerador, siderúrgico, petrolífero, bancário, automotivo, têxtil, 
Relações bilaterais Brasil-Argentina: implicações para a integração regional

Amanda Ferreira

Jonathan de Araújo de Assis

Julia de Souza Borba Gonçalve

Rúbia Áisa Marcondes da Fonseca

Vitor Garcia de Oliveira Raymundo

calçadista, de máquinas agrícolas e de construção civil” XIV. . Ademais, ainda segundo o Ministério, a presença de capitais argentinos no Brasil é bastante significativa.

\section{DESENVOLVIMENTO}

Primeiramente, cabe analisar-se o comportamento político dos dois países. Em 2007, era bastante notável o esforço por parte de ambos em estabelecer um clima de amizade e parceria, visando um aumento na integração regional. Esse sentimento se refletiu por meio de mútuos apoios em posicionamentos na política exterior, possuindo como casos emblemáticos a abstenção tanto do Brasil quanto da Argentina, juntamente com outros países, na votação do Conselho de Direitos Humanos da Organização das Nações Unidas (ONU) sobre uma resolução pedindo a proibição da difamação pública de religiões e reivindicando que a liberdade de expressão seja exercida com responsabilidade, e, portanto, que esteja sujeita às limitações da lei, a ocasião em que o presidente Lula e seu homólogo Néstor Kirchner uniram-se para cobrar do presidente boliviano, Evo Morales, durante a Cúpula do Mercosul, um aumento na exportação de gás para seus respectivos países e a apresentação em Genebra, por parte do Brasil,de uma proposta para a criação de metas de direitos humanos na ONU ,a qual recebeu apoio da Argentina.

Em relação à atuação em organismos internacionais (regionais ou não), ambos os países tiveram as mesmas posturas e expressaram os mesmos valores em várias oportunidades: a Argentina deu apoio à proposta brasileira de regulação dos subsídios de pesca na Organização Mundial do Comércio (OMC) e o Brasil, por sua vez, defendeu a reintegração das Ilhas Malvinas à Argentina durante a Cúpula da América Latina e Caribe (Calc) e condenou a exploração de petróleo na região pela Grã-Bretanha, além de criticar a ONU por não defender o país vizinho, cobrando da Organização uma ação mais eficaz na disputa. No âmbito regional, os dois países firmaram o acordo de substituição do dólar por peso ou real nas transações comerciais, fixando a taxa cambial de referência ao Brasil ou à Argentina e ao câmbio de mercado. Durante a crise econômica de 2008, defenderam ainda a estatização dos bancos, além de concordarem em elevar a Tarifa Externa Comum do Mercosul sobre as importações de alguns produtos procedentes de países não participantes do bloco e em coordenar políticas comerciais para limitar o fluxo de produtos chineses em seus mercados.

No que tange as posições brasileira e argentina em relação à promoção de regimes democráticos, ambos os países atuam de forma convergente ao procurarem estabelecer uma cooperação com vistas à consolidação da democracia, atuando de forma mais incisiva em âmbito regional. As duas nações, que passaram por períodos conturbados política e economicamente, atravessando períodos de regimes ditatoriais e crises econômicas, iniciaram a partir da década de 1980 suas respectivas redemocratizações e começaram a estabelecer políticas de compromisso com, entre outros temas, a democracia ${ }^{\mathrm{XV}}$. Desde 1985, o Brasil buscou fortalecer-se e melhorar sua imagem internacionalmente, e tem tratado a questão da defesa da democracia como pauta fundamental de sua política externa, procurando consolidar

Cadernos do Tempo Presente, n. 24, jun./jul. 2016, p. 120-135| http://www.seer.ufs.br/index.php/tempo 
Relações bilaterais Brasil-Argentina: implicações para a integração regional

Amanda Ferreira

Jonathan de Araújo de Assis

Julia de Souza Borba Gonçalve

Rúbia Áisa Marcondes da Fonseca

Vitor Garcia de Oliveira Raymundo

sua influência internacional participando de forma ativa em foros e instituições regionais sempre pautando sua conduta em prol dos valores democráticos. A Argentina também procurou fazer parte de grupos e instituições que tivessem entre seus objetivos a manutenção da estabilidade da ordem dos regimes políticos na região.

Assim, os dois países aderiram aos principais acordos e instrumentos que visam a defesa de regimes democráticos. Em 1991, como membros da Organização dos Estados Americanos (OEA), participaram dos debates sobre o tema que levaram ao Compromisso de Santiago com a Democracia e a Renovação do Sistema Interamericano e a Resolução 1080 (AG/RES, 1080 XXI-O/91) XVI, acrescentada em 2001 pela Carta Democrática Interamericana $^{\mathrm{XVII}}$. Estiveram bastante engajados também nos diversos mecanismos democráticos estabelecidos pelo Grupo do Rio ${ }^{\mathrm{XVIII}}$, que estabelecem a ocorrência de reuniões de emergência em casos de ameaça à democracia.

O engajamento com a questão da democracia foi trazido também para o âmbito do Mercosul. No ano de 1998, a partir do Protocolo de Ushuaia sobre Compromisso Democrático no Mercosul, Bolívia e Chile, foi incorporada aos acordos de integração que compõem o bloco a cláusula democrática, que prevê consultas e possíveis sansões, acordadas previamente entre os países-membros, a rupturas da ordem democrática em nações signatárias do Protocolo ${ }^{\mathrm{XIX}}$.

Em 2009, Argentina e Brasil elaboraram de forma conjunta uma declaração na qual não reconheciam as eleições hondurenhas, ocorridas neste país meses após um golpe de Estado e, em decorrência do mesmo fato, em 2010, ambas as nações exerceram pressão para que Honduras não participasse da VI Cúpula América Latina e Caribe-UE. No mesmo ano, os dois países atuaram como principais incentivadores da criação de um mecanismo dentro da Unasul que prevê a aplicação de sanções nas esferas política, econômica e comercial aos países que tivessem sua ordem institucional ameaçada por golpes de Estado - o Protocolo Adicional ao Tratado Constitutivo da Unasul sobre Compromisso com a Democracia, assinado em Georgetown, Guiana, no ano de 2010.

Esse comportamento político de Brasil e Argentina foi um fator que colaborou para que se instalasse um momento de crescente cooperação, que se deu de forma mais regional principalmente nas questões energéticas, como na Cúpula Energética da Comunidade SulAmericana de Nações (ano), ocorrida na Venezuela, onde se criou um conselho energético da América do Sul com o objetivo de aproximar seus membros na coordenação de obras de infraestrutura para a integração energética regional na área de hidrocarbonetos, energia hidroelétrica e também nas políticas de biocombustíveis. Bilateralmente, a discussão sobre o assunto em reuniões entre os dois países apontava para o interesse em parcerias nas áreas de energia hidrelétrica, termelétrica, nuclear, eólica e biodiesel, além de terem havido debates sobre a construção da hidrelétrica de Garabi, na fronteira entre Brasil e Argentina, e o desenvolvimento de programas de produção de energia nuclear conjunta.

Tais negociações tiveram efeito prático quando diante da crise energética enfrentada pela Argentina em 2007, o Brasil assinou um acordo com o país vizinho que previa a exportação de 700 megawatts médios de energia elétrica e, a pedido de Nestor Kirschner, o presidente Lula autorizou o aumento do volume de energia enviado à Argentina, além de consentir que o governo boliviano enviasse parte do gás natural que seria destinado ao Brasil 
Relações bilaterais Brasil-Argentina: implicações para a integração regional

Amanda Ferreira

Jonathan de Araújo de Assis

Julia de Souza Borba Gonçalve

Rúbia Áisa Marcondes da Fonseca

Vitor Garcia de Oliveira Raymundo

ao país vizinho, o qual poderia vira enfrentar uma crise energética em razão do frio da estação. É importante ressaltar também que em outros momentos a Bolívia foi envolvida nesse processo de formulação de acordos, o que pode ter resultado em facilidades na integração regional. Ainda em 2007, a base antártica argentina Esperanza chegou a ser abastecida por alguns meses pelo navio brasileiro de apoio oceanográfico Ary Rongel, devido ao incêndio do navio argentino Almirante Irizar.

A partir da cláusula democrática da Unasul, a Argentina e o Brasil, juntamente com os outros países signatários do Protocolo de Ushuaia do Mercosul, produziram em 2011 na cidade de Montevidéu, Uruguai, o Protocolo de Ushuaia II, que prevê, entre as medidas que podem ser tomadas, a aplicação de sanções e a suspensão de um dos membros do bloco em caso de ruptura ou ameaça de ruptura do regime político democrático. Esse mecanismo democrático, assim como o da Unasul, teve papel fundamental ao assegurar a atuação dos países em relação a conflitos políticos internos em países da América do Sul. Em 2012, a crise política vivida pelo Paraguai que culminou com o impeachment do presidente uruguaio Fernando Lugo, levou o Brasil e a Argentina, juntamente com o Uaraguai, a suspenderem o país do Mercosul. A crise também levou à suspensão paraguaia da Unasul até a comprovação do reestabelecimento da ordem democrática.

Podemos perceber que tanto o Brasil como a Argentina se mostram favoráveis à atuação conjunta a fim de se estabelecer medidas que visem uma maior integração regional. Em relação à Defesa, estabeleceram acordos que preveem a criação de uma empresa binacional responsável pelo enriquecimento de urânio e a criação de um reator nuclear para atender as demandas energéticas da região, o controle da Embraer sobre a produção de aviões argentinos e a compra destes pelo Brasil - e ainda, a participação da empresa em mais 16 acordos bilaterais de defesa - e o desenvolvimento de um veículo militar para o transporte de tropas. Também acordaram em estabelecer medidas que inibam a tensão bélica na região e se posicionaram contra a presença de bases militares de potências estrangeiras na América do Sul.

Nas demais relações que incluem cooperação bilateral, inclui-se o convênio do Banco Nacional de Desenvolvimento Econômico e Social (BNDES) com o Banco de La Nación Argentina para a geração de uma fonte de crédito para empresas de ambos os países que invistam em projetos locais, o investimento brasileiro no Banco Central Argentino, visando garantir reservas internacionais ao país vizinho, a adoção conjunta do modelo nipo-brasileiro de televisão digital (a decisão reafirma a intenção de ambos os países de trabalharem juntos para que a região siga crescendo econômica e socialmente) e a postura conjunta em firmar o tratado de criação do Banco do Sul para projetos de infraestrutura regional. Ademais, outras áreas de cooperação também podem ser citadas como saúde, educação, meio ambiente e turismo, bem como o compromisso de uma reunião técnica para a implantação de corredores interoceânicos, os quais envolveriam também a Bolívia e o Paraguai.

$\mathrm{Na}$ economia, percebemos que Brasil e Argentina aproximaram-se em seus posicionamentos em fóruns internacionais, fato que pode ser considerado uma vantagem para o desenvolvimento de suas relações bilaterais e a nível regional, como no âmbito do Mercosul. Isso pode ser observado na tentativa argentina de promover uma declaração conjunta dos países do G-20 em apoio à postura brasileira de não aceitar as ofertas dos 


Relações bilaterais Brasil-Argentina: implicações para a integração regional
Amanda Ferreira
Jonathan de Araújo de Assis
Julia de Souza Borba Gonçalve
Rúbia Áisa Marcondes da Fonseca
Vitor Garcia de Oliveira Raymundo

Estados Unidos e da União Europeia quanto à liberalização comercial, além do apoio da Argentina frente ao pedido do Brasil de aumentar em 35\% a Tarifa Externa Comum (TEC) de calçados, móveis, têxteis e confecções no âmbito do Mercosul. Além disso, em Genebra, Brasil e Argentina defenderam que fossem garantidas flexibilidades a fim de se permitir que setores mais sensíveis da indústria do Mercosul não fossem liberalizados.

Contudo, cabe ressaltar que o Brasil, ainda que tenha o mercado argentino como um forte aliado, empenha-se também nas negociações multilaterais, mesmo que essas vão contra os interesses argentinos, tendo como exemplo a recusa por parte do governo brasileiro do pedido argentino de redução da importação do gás boliviano para favorecer a importação do gás argentino. Outro caso emblemático referente a esse ponto foi o impasse decorrido da irregularidade no fornecimento de trigo argentino ao Brasil, correspondente a $70 \%$ da importação brasileira. Tal irregularidade poderia gerar instabilidade do preço do trigo e ameaça de desabastecimento, levando o Brasil a adotar como medida alternativa a liberação das importações sem impostos advindas de outros países não membros do Mercosul.

Em 2007, estava em pauta a discussão sobre o Banco do Sul. Os dois maiores incentivadores do Banco seriam os presidentes da Venezuela, Hugo Chávez, e da Argentina, Nestor Kirchner, que afirmaram ser a instituição uma alternativa ao Banco Mundial e ao Fundo Monetário Internacional (FMI). Em reunião com o ministro da Fazenda brasileiro, Guido Mantega, a ministra da Economia argentina, Felisa Miceli, fez o convite ao Brasil para também fazer parte da comissão de criação do banco. Em encontro sobre o tema, o Brasil participou ainda como observador, mostrando interesse em participar como sócio pleno do banco e se envolvendo bastante no projeto. Entretanto, Lula desejava que ele servisse como investidor de obras de infra-estrutura na região, posicionamento que gerou um certo entrave nas negociações, fazendo com que o presidente venezuelano, Hugo Chávez, afirmasse que não esperariam pelo Brasil para a criação do Banco do Sul.

Ainda sobre as questões econômicas, em 2007, os dois países decidiram estudar a criação de um fundo de prevenção contra ataques especulativos as suas moedas nacionais. $\mathrm{O}$ objetivo do fundo, formado pelos Bancos Centrais de ambos os países, seria socorrer um ao outro caso houvesse emergência e falta de liquidez em um desses. A discussão, embora inicialmente envolvesse apenas Brasil e Argentina, poderia incluir futuramente o Uruguai e outros países da América Latina.

Ademais, outro ponto de destaque nas relações econômicas entre Brasil e Argentina tem como foco a Petrobrás, devido à Petrobras Energía, que atua em território argentino. Quanto a isso, alternaram-se momentos em que a Argentina pedia mais investimentos da empresa no país, ideia compartilhada também pela empresa brasileira, e períodos em que os lucros da Petrobrás na Argentina diminuíram devido ao congelamento do preço das tarifas dos combustíveis determinado pelo então presidente Néstor Kirchner.

As divergências nas questões econômicas também ocorreram no período analisado. Em 2007, era perceptível uma busca tanto do Brasil quanto da Argentina em amenizá-las, de forma que não superassem os esforços de cooperação. Como exemplo dessas discordâncias, temos a nota da União Industrial Argentina (UIA) criticando a aprovação pelo Congresso 
brasileiro de lei que regulamenta a criação de zonas de processamento de exportações (ZPEs), o processo aberto pela Argentina contra o Brasil na OMC com a acusação contra a sobretaxa imposta pelo governo brasileiro à entrada de resina PET argentina no país e a proposta argentina para os demais países do Mercosul de taxar a exportação de produtos agrícolas que provocou reações negativas entre parlamentares brasileiros.

Em contrapartida, com o advento da crise internacional, em 2008, pode-se perceber que os dois países, sob o discurso de defesa de suas economias, adotaram medidas divergentes: por um lado, o Brasil, buscando reforçar seu papel como líder regional, defendeu a liberalização do comércio e a Argentina, por outro lado, aplicou protecionismo aos produtos brasileiros, por receio de que a liberalização pudesse implicar em efeitos negativos para sua economia interna - o país chegou a apresentar uma lista de restrição a 767 produtos brasileiros, resultando na perda de $17,3 \%$ no destino das exportações brasileiras. Frente ao protecionismo argentino, o Brasil buscou mecanismos viáveis para garantir que a entrada de seus produtos no mercado daquele, tais como a retomada de cotas de exportação para evitar medidas unilaterais do país vizinho e ao mesmo tempo contemplar suas exigências sem maiores prejuízos à indústria local, além da oferta de crédito para empresas argentinas que exportam para o Brasil e a limitação da exportação de seis setores, como calçados e móveis.

Além disso, no decorrer do mesmo ano, várias reuniões entre os dois países foram feitas a fim de se chegar a um acordo que beneficiasse a ambos. No entanto, alguns acordos firmados não foram capazes de acabar com os atritos entre os dois países. As relações comerciais foram marcadas majoritariamente por restrições de produtos ou aplicação de licenças não automáticas como forma de retaliação de um país para o outro, e resultaram na queda de $92 \%$ do saldo comercial brasileiro em relação à Argentina. As exportações brasileiras para a Argentina voltaram a aumentar em função das reclamações e ameaças de retaliações comerciais que vinham sendo feitas pelo Brasil. Isso demonstra o peso econômico do Brasil.

\section{CONCLUSÃO}

Dessa forma, foi possível observar que no geral Brasil e Argentina passaram no período abordado por um momento de busca pelo estabelecimento de uma parceria, sendo esta um meio para se chegar ao objetivo de uma integração regional mais aprofundada, meta que tem o Mercosul como possível alavanca. Porém, em matéria de comércio bilateral os dois países tiveram posturas divergentes em boa parte do tempo, principalmente durante a crise de 2008, a qual representou momento de maior tensão entre os dois. Esta se deu às diferentes posturas adotas pelos dois países visando a superação da crise, e principalmente à mudança de posicionamento brasileiro na questão da liberalização do comércio.

É interessante notar que mesmo que as relações bilaterais tenham passado por momentos complicados em meio a crise, a postura conjunta de Brasil e Argentina no âmbito regional permaneceu. O maior exemplo disso é no Mercosul, em que as propostas dos dois 
Relações bilaterais Brasil-Argentina: implicações para a integração regional

Amanda Ferreira

Jonathan de Araújo de Assis

Julia de Souza Borba Gonçalve

Rúbia Áisa Marcondes da Fonseca

Vitor Garcia de Oliveira Raymundo

países continuaram convergentes, fato que criou um clima de estabilidade entre eles e pôde fazer com que o andamento do grupo fluísse mais facilmente, visto que Brasil e Argentina são os países de maior influência no mesmo, ainda que hajam posicionamentos divergentes quanto a essa questão.

\title{
NOTAS
}

\footnotetext{
I Graduanda em Relações Internacionais pela UNESP - Franca, membro do Grupo de Estudos de Defesa e Segurança Internacional (GEDES) e do Observatório de Política Exterior (OPEx) desde 2013. Email: amandafr@outlook.com
}

\begin{abstract}
" Mestrando em Relações Internacionais pelo Programa de PPGRI Santiago Dantas (UNESP-UNICAMPPUC/SP). Membro do Observatório de Política Exterior, e redator do produto de análise mensal. Pesquisador no Grupo de Estudos de Defesa e Segurança Internacional (GEDES).

III Graduanda em Relações Internacionais pela UNESP - Franca, membro do Observatório de Política Exterior (OPEx) do Grupo de Estudos de Defesa e Segurança Internacional (GEDES). Email: juli.borbagoncalves@gmail.com
\end{abstract}

IV Graduanda em Relações Internacionais pela UNESP - Franca, membro do Grupo de Estudos de Defesa e Segurança Internacional (GEDES) e do Observatório de Política Exterior (OPEx). Email: rubia.a.fonseca@gmail.com

V Bacharel em Relações Internacionais pela UNESP - Franca e graduando em Jornalismo na Escola de Comunicações e Artes da Universidade de São Paulo (ECA-USP). Email: vitorgarciaoliveira@gmail.com

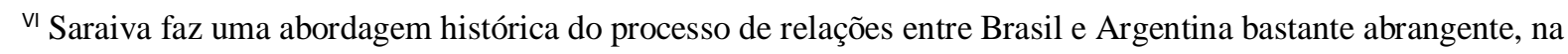
qual podemos observar os fatos e contextos em que se deram as ações mútuas de política externa dos dois países.

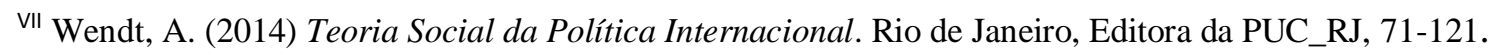

VIII Ministério Das Relações Exteriores. República Argentina. Disponível em: http://www.itamaraty.gov.br/index.php?option=com_content $\&$ view=article\&id=4785\&Itemid=478\&cod_pais= ARG\&tipo=ficha_pais\&lang=pt-BR. (Consult.: 01 abril 2015).

\footnotetext{
${ }^{\mathrm{Ix}}$ De acordo com dados do Banco Mundial, em 2014, o PIB brasileiro cresceu somente 0,1\% (em oposição aos $2,5 \%$ de incremento do ano anterior) e o argentino sofreu retração de 1,5\% (em 2013, o crescimento foi de 2,9\%)

X Levando em consideração, o período 2003-2013, o fluxo comercial entre os países sofreu contínuo incremento até 2013, com exceção de 2009 - ano no qual os países em desenvolvimentos foram atingidos mais fortemente pelos efeitos da crise mundial iniciado nos EUA no ano anterior - e 2012, nos quais houve retração.
}

Cadernos do Tempo Presente, n. 24, jun./jul. 2016, p. 120-135| http://www.seer.ufs.br/index.php/tempo 
Relações bilaterais Brasil-Argentina: implicações para a integração regional

Amanda Ferreira

Jonathan de Araújo de Assis

Julia de Souza Borba Gonçalve

Rúbia Áisa Marcondes da Fonseca

Vitor Garcia de Oliveira Raymundo

Segundo informações do Ministério das Relações Exteriores e do Ministério do Desenvolvimento, Indústria e Comércio, nesse período (2003-2013), "a corrente de comércio bilateral elevou-se de US\$9,24 bilhões para US\$ 36,08 bilhões, um crescimento de $290 \%$ [e] (...) as exportações brasileiras para a Argentina cresceram de US\$ 4,56 bilhões para US\$19,61 bilhões, incremento de $330 \%$.

${ }^{\mathrm{x}}$ Segundo relatório do Ministério do Desenvolvimento, Indústria e Comércio, o valor das exportações brasileiras para a Argentina passou de aproximadamente US\$19,6 bilhões, em 2013, para US\$14,2 bilhões, em 2014. No que se refere às importações, essas contabilizavam cerca de US\$16,4 bilhões, em 2013, e passaram para U\$S14,1 bilhões, em 2014.

XII Todos os dados apresentados foram retirados do site do Ministério do Desenvolvimento, Indústria e Comércio do Brasil, na seção "Intercâmbio comercial brasileiro: Países e Blocos”.

XIII Além dessa categoria de produto, apenas os enquadrado como "Produtos do Reino Animal" sofreram aumento de vendas $(9,32 \%)$. Todos os outros produtos sofreram diminuição de exportações.

XIV Ministério Das Relações Exteriores. República Argentina. Disponível em: http://www.itamaraty.gov.br/index.php?option=com_content\&view=article\&id=4785\&Itemid=478\&cod_pais= ARG\&tipo=ficha_pais\&lang=pt-BR. (Consult.: 01 abril 2015).

XV A abertura política também proporcionou a aproximação de Brasil e Argentina, fator que abriu caminhos para a criação do Mercosul, órgão pautado nos princípios da democracia e do desenvolvimento econômico.

${ }^{X V I}$ Possuem como finalidade garantir instrumentos de respaldo para uma ação coletiva dos membros da Organização em caso de ruptura de um regime democrático. Em instrumento complementar aprovado em 1992, insere-se a possibilidade de suspensão de membros da organização em caso de golpes contra a estabilidade política dos governos.

XVII A Carta Democrática Interamericana foi concebida a partir da necessidade de um instrumento dentro da OEA que desse as diretrizes de ação dos membros no caso de ameaça à democracia que ainda não tenha levado à ruptura política. Teve como motivo a crise democrática do Peru, iniciada em 2000.

xvIII Grupo formado por Argentina, Brasil, Colômbia, México, Panamá, Peru, Uruguai e Venezuela em 1986. O grupo baseia-se na tomada de decisões por consenso e realiza reuniões de cúpula anualmente. Tem suas ações baseadas nos acordos: Declaração de Quito (1995), Declaração a respeito da Manutenção da Democracia (1997), Compromisso Democrático de Cartagena (2000) e Declaração de São José (2002).

XIx Aderiram ao Protocolo de Ushuaia os países-membros do Mercosul, assim como as Repúblicas da Bolívia e do Chile. Posteriormente, Venezuela (2005), Peru (2005) e Equador (2007) também aderiram à cláusula democrática do bloco sul-americano.

\section{Referências Bibliográficas}

Cadernos do Tempo Presente, n. 24, jun./jul. 2016, p. 120-135| http://www.seer.ufs.br/index.php/tempo 


\section{Relações bilaterais Brasil-Argentina: implicações para a integração regional \\ Amanda Ferreira \\ Jonathan de Araújo de Assis \\ Julia de Souza Borba Gonçalve \\ Rúbia Áisa Marcondes da Fonseca \\ Vitor Garcia de Oliveira Raymundo}

Associação De Comércio Exterior do Brasil. (2012) Radiografia do comércio exterior brasileiro: passado, presente e futuro (online). Disponível em: http://www.aeb.org.br/userfiles/file/AEB\%20z20Radiografia\%20Com\%C3\%A9rcio\%20Exterior\%20Brasil.pdf. (Consult.: 02 abril 2015).

Figueira, A. C. R. (2011) Democracia e política externa. $3^{\circ}$ Encontro Nacional ABRI 2001, 2011, São Paulo (SP, Brazil) (online). Disponível em: $<$ http://www.proceedings.scielo.br/scielo.php?script=sci_arttext\&pid=MSC00000001220110 00100027\&lng=en\&nrm=iso> (Consult.: 29 março 2015).

Flemes, D.; Nolte D.; Whner L. (2011) Una comunidad de seguridad regional en formación: La Unasur y su Consejo de Defensa. Estudios Internacionales, n. 170, 105-127.

Mello, L. I. A. (1966) Argentina e Brasil: a balança de poder no Cone Sul, São Paulo, Annablume.

Mercosur. Protocolo de Ushuaia (online). Disponível em: http://www.mercosur.int/innovaportal/v/4824/1/secretaria/tratados_protocolos_e_acordos_dep ositados_no_paraguai (Consult.: 29 março 2015)

Mercosur. Protocolo de Montevidéu sobre compromisso com a democracia no Mercosul (Ushuaia II) (online). Disponível em: http://www.mercosur.int/innovaportal/file/2486/1/ushuaia_ii.pdf. (Consult.: 02 abril 2015).

Ministério Das Relações Exteriores. República Argentina. Disponível em: http://www.itamaraty.gov.br/index.php?option=com_content $\&$ view=article $\&$ id=4785\&Itemid $=478 \&$ cod_pais=ARG\&tipo=ficha_pais\&lang=pt-BR. (Consult.: 01 abril 2015).

Ministério das Relações Exteriores, Departamento de Promoção Comercial e Investimento; Divisão de Inteligência Comercial. (2014) Brasil: Comércio exterior (dados até janeiro 2014).

Disponível em: http://www.brasilexport.gov.br/sites/default/files/publicacoes/indicadoresEconomicos/ComEx tBrasileiroFEV2014.pdf. (Consult.: 02 abril 2015).

Observatório de Política Exterior do Brasil. (2007a) Brasil se abstém em votação da ONU e é criticado. Franca, Grupo de Estudos de Defesa e Segurança Internacional, n. 121.

Observatório de Política Exterior do Brasil. (2007b) Brasil participou de acordo para formação do Banco do Sul. Franca, Grupo de Estudos de Defesa e Segurança Internacional, n. 122. 


$$
\begin{gathered}
\text { Relações bilaterais Brasil-Argentina: implicações para a integração regional } \\
\text { Amanda Ferreira } \\
\text { Jonathan de Araújo de Assis } \\
\text { Julia de Souza Borba Gonçalve } \\
\text { Rúbia Áisa Marcondes da Fonseca } \\
\text { Vitor Garcia de Oliveira Raymundo }
\end{gathered}
$$

Observatório de Política Exterior do Brasil. (2007c) Brasil pode elevar taxa para calçados e têxteis sem acordo no Mercosul. Franca, Grupo de Estudos de Defesa e Segurança Internacional, n. 122.

Observatório de Política Exterior do Brasil. (2007d) Conselho energético sul-americano foi criado na Venezuela. Franca, Grupo de Estudos de Defesa e Segurança Internacional, n. 127.

Observatório de Política Exterior do Brasil. (2007e) Informe de Política Externa Brasileira. Franca, Grupo de Estudos de Defesa e Segurança Internacional, n. 125.

Observatório de Política Exterior do Brasil. (2007f) Informe de Política Externa Brasileira. Franca, Grupo de Estudos de Defesa e Segurança Internacional, n. 127.

Observatório de Política Exterior do Brasil. (2007g) Brasil fechou acordo sobre energia com $o$ Chile. Franca, Grupo de Estudos de Defesa e Segurança Internacional, n. 129.

Observatório de Política Exterior do Brasil. (2007h) Informe de Politica Externa Brasileira. Franca, Grupo de Estudos de Defesa e Segurança Internacional, n. 131.

Observatório de Política Exterior do Brasil. (2007i) Brasil assinou acordo energético com Argentina. Franca, Grupo de Estudos de Defesa e Segurança Internacional, n. 134.

Observatório de Política Exterior do Brasil. (2007j) Brasil enviará mais eletricidade à Argentina. Franca, Grupo de Estudos de Defesa e Segurança Internacional, n. 138.

Observatório de Política Exterior do Brasil. (2007k) Brasil viaja à Argentina. Franca, Grupo de Estudos de Defesa e Segurança Internacional, n. 138.

Observatório de Política Exterior do Brasil. (20071) Lula declara que não recuará na Rodada Doha. Franca, Grupo de Estudos de Defesa e Segurança Internacional, n. 138.

Observatório de Política Exterior do Brasil. (2007m) Indústrias argentinas criticam criação de ZPE's. Franca, Grupo de Estudos de Defesa e Segurança Internacional, n. 140.

Observatório de Política Exterior do Brasil. (2007n) Banco do Sul será feito sem o Brasil. Franca, Grupo de Estudos de Defesa e Segurança Internacional, n. 142.

Observatório de Política Exterior do Brasil. (2007o) Brasil propôs na ONU metas de direitos humanos. Franca, Grupo de Estudos de Defesa e Segurança Internacional, n. 147.

Observatório de Política Exterior do Brasil. (2007p) EUA cobram de Brasil e G20 maior abertura industrial. Franca, Grupo de Estudos de Defesa e Segurança Internacional, n. 149. 


$$
\begin{aligned}
& \text { Relações bilaterais Brasil-Argentina: implicações para a integração regional } \\
& \text { Amanda Ferreira } \\
& \text { Jonathan de Araújo de Assis } \\
& \text { Julia de Souza Borba Gonçalve } \\
& \text { Rúbia Áisa Marcondes da Fonseca } \\
& \text { Vitor Garcia de Oliveira Raymundo }
\end{aligned}
$$

Observatório de Política Exterior do Brasil. (2007q) Brasil prestará ajuda a base argentina. Franca, Grupo de Estudos de Defesa e Segurança Internacional, n. 152.

Observatório de Política Exterior do Brasil. (2007r) Argentina abriu processo contra o Brasil na OMC. Franca, Grupo de Estudos de Defesa e Segurança Internacional, n. 155.

Observatório de Política Exterior do Brasil. (2007t) Parlamentares brasileiros mostraram-se contrários a proposta argentina. Franca, Grupo de Estudos de Defesa e Segurança Internacional, n. 156.

Observatório de Política Exterior do Brasil. (2007u) Informe de Política Externa Brasileira. Franca, Grupo de Estudos de Defesa e Segurança Internacional, n. 156.

Observatório de Política Exterior do Brasil. (2008a) Brasil oferece à Argentina energia elétrica e combustível nuclear. Franca, Grupo de Estudos de Defesa e Segurança Internacional, n. 158.

Observatório de Política Exterior do Brasil. (2008b) Brasil e Argentina fecham uma série de acordos bilaterais. Franca, Grupo de Estudos de Defesa e Segurança Internacional, n. 159.

Observatório de Política Exterior do Brasil. (2008c) Argentina deve resolver crise interna antes de exportar trigo para o Brasil. Franca, Grupo de Estudos de Defesa e Segurança Internacional, n. 167.

Observatório de Política Exterior do Brasil. (2008d) Embraer fará parte de acordos bilaterais. Franca: Grupo de Estudos de Defesa e Segurança Internacional, n. 183.

Observatório de Política Exterior do Brasil. (2008e) Representantes latino-americanos reuniram-se em Brasília. Franca, Grupo de Estudos de Defesa e Segurança Internacional, n. 190.

Observatório de Política Exterior do Brasil. (2009a) Brasil apresenta plano contra o protecionismo da Argentina. Franca, Grupo de Estudos de Defesa e Segurança Internacional, n. 198.

Observatório de Política Exterior do Brasil. (2009b) Brasil admite aceitar cotas para exportar à Argentina. Franca, Grupo de Estudos de Defesa e Segurança Internacional, n. 200.

Observatório de Política Exterior do Brasil. (2009c) BNDES estuda convênio com o Banco de la Nación Argentina. Franca, Grupo de Estudos de Defesa e Segurança Internacional, n. 203.

Observatório de Política Exterior do Brasil. (2009d) Brasil investiu US\$ 1,5 bi na Argentina. Franca, Grupo de Estudos de Defesa e Segurança Internacional, n. 214. 


Relações bilaterais Brasil-Argentina: implicações para a integração regional
Amanda Ferreira
Jonathan de Araújo de Assis
Julia de Souza Borba Gonçalve
Rúbia Áisa Marcondes da Fonseca
Vitor Garcia de Oliveira Raymundo

Observatório de Política Exterior do Brasil. (2009e) Lula se queixou de barreiras à presidente da Argentina. Franca, Grupo de Estudos de Defesa e Segurança Internacional, n. 220.

Observatório de Política Exterior do Brasil. (2009f) Argentina escolheu padrão de TV digital igual ao brasileiro. Franca, Grupo de Estudos de Defesa e Segurança Internacional, n. 225.

Observatório de Política Exterior do Brasil. (2009g) Ministros de Defesa da Unasul reuniram-se no Equador. Franca, Grupo de Estudos de Defesa e Segurança Internacional, n. 227.

Observatório de Política Exterior do Brasil. (2009h) Ministros de Brasil e Argentina encontraram-se em São Paulo. Franca, Grupo de Estudos de Defesa e Segurança Internacional, n. 228.

Observatório de Política Exterior do Brasil. (2009i) Brasil barrou autopeças argentinas. Franca, Grupo de Estudos de Defesa e Segurança Internacional, n. 235.

Observatório de Política Exterior do Brasil. (2009j) Brasil e Argentina posicionam-se contra bases militares. Franca, Grupo de Estudos de Defesa e Segurança Internacional, n. 236.

Observatório de Política Exterior do Brasil. (2009k) Brasil reafirma que não reconhece eleições em Honduras. Franca, Grupo de Estudos de Defesa e Segurança Internacional, n. 239.

Observatório de Política Exterior do Brasil. (2010) Brasil e América Latina defendem reintegração das Ilhas Malvinas à Argentina. Franca, Grupo de Estudos de Defesa e Segurança Internacional, n. 245.

Observatório de Política Exterior do Brasil. Informes Do período de 2007 a 2010. Disponível em:

http://www.gedes.org.br/produto.php?acao $=$ exibePublicacoes\&idPublicacoes $=54 \&$ produto $=0$ bservat\%C3\%B3rio\%20de\%20Pol\%C3\% ADtica\%20Exterior\&\&cat=Informe\%20Brasil\#arch orPublicacoes> (Consult.: 25 setembro 2014).

Russel, R. \& Tokatlian, J. G. (2002) El lugar del Brasil en la política exterior de la Argentina: La visión del otro. Desarrollo Económico, v. 42, n. 167, 405-428.

Santiso, C. (2002) Promoção e proteção da democracia na política externa brasileira.Contexto internacion (online), vol. 24. Disponível em: <http://www.scielo.br/scielo.php?pid=S0102$85292002000200002 \&$ script=sci_arttext $>$ (Consult.: 02 abril 2015). 
Saraiva, M. G. (2012) Encontros e desencontros: o lugar da Argentina na política externa brasileira. Belo Horizonte, Fino Traço.

Soares, S.A., MOTTA, B. V. C. (2014) Argentina e Brasil: uma cultura estratégica conjunta em adagio. Latitud Sur.

Unasur. (2014) Protocolo adicional al Tratado Constitutivo de UNASUL sobre compromisso com la democracia. Disponível em: http://www.unasursg.org/images/descargas/DOCUMENTOS\%20CONSTITUTIVOS\%20DE $\%$ 20UNASUR/Protocolo-Adicional-al-Tratado-Constitutivo-de-UNASUR-sobreCompromiso-con-la-Democracia-opt.pdf (Consult.: 02 abr. 2015)

Wendt, A. (2014) Teoria Social da Política Internacional. Rio de Janeiro, Editora da PUC_RJ, 71-121. 